\title{
A General Approach Students' Attitude towards to Virtual Reality Technology in Distance Education Environment
}

\author{
Mohamed Abdelsalam ${ }^{a *}$, Ayman E. Khedr ${ }^{b}$, Osama Emam ${ }^{b^{*}}$, and Yehia Helmy ${ }^{a}$ \\ ${ }^{a}$ Faculty of Commerce \& Business Administration, Helwan University, Egypt \\ ${ }^{b}$ Faculty of Computers and Information Helwan University, Egypt. \\ *emam_o_e@yahoo.com
}

\begin{abstract}
E-learning has become a prominent and effective role in recent years. The factor of place and time became ineffective in the educational process. So that anyone can learn anywhere in the world. The educational services that benefit the learner during the educational process as well as the factors of assistance are important elements that help in the success of the educational process in the environment of e-learning. The more these services, the greater the benefit from e-learning. But its way of reviewing electronic content is still ineffective. Therefore it was necessary to create a suitable environment for the learner is similar to the real reality. Through which the learner feels the integration and concentration in the academic content as if it were realistic. So, the trend was to take advantage of the virtual reality technology that have become effective in all fields. The use of this technology will help the learner gain more realism and make full use of the electronic content. This study reviews the effect of the use of virtual reality technology in the review of the learner's electronic content, as well as the attitudes and opinions of the students of the Business Information Systems program at the Faculty of Commerce, Helwan University, Cairo, Egypt, about the use of this technology and to what extent will effect on change and effectiveness in the quality of educational process.
\end{abstract}

Keywords: Learning, Distance Education, Educational Process, Virtual Reality (VR)

\section{Introduction}

In recent years, technology has had the greatest impact in the development the educational environment and has led to the construction of a new learning environment that helps learners to increase knowledge. At present, virtual reality technology has become a new trend for all fields, especially in education.

Virtual reality is "a computer-generated simulation of a 3D environment, which seems very real to the person experiencing it, using special electronic equipment. The objective is to achieve a strong sense of being present in the virtual environment" [1]. In addition, simulation of tools and their action against the organs in the virtual environment is also required [2].

Virtual reality is not new. It has been here for decades, [3] immersive VR technologies have been present in our lives for decades. Even as far back as the 1960's, research labs were exploring ways to replace or augment our physical world with computer data.
Early of 90's, the first enterprise VR appeared in the form of computers costing upwards of $\$ 40,000$, and consumer VR started to appear alongside Nintendo and Sega gaming consoles.

Virtual reality cost up to $\$ 73,000$, and a number of accessories sprung into the market to try and augment digital experiences [3].

Today's VR technology need for wearing a Head Mounted Display (HMD) to view stereoscopic 3D scenes. Anyone use HMD can moving your head for looking around, and using hand controls or motion sensors for walking around. In addition, involving in a fully immersive experience. It's as if you're really there in some other virtual world [1]. The following Figure shows example of HMD.

Figure 1: Example of HMD

The features of VR technology include perception, presence, interactivity, etc. Besides the common visual perception of computer system, it also produces convincing auditory, tactile, and motion perception. The ideal digital environment created by VR 
technology helps users perceive everything as true as in reality [4].

In today's world of limited attention spans, virtual reality plays an important role in providing immediate engagement with the learning system. By making VR experiences truly immersive, distractions are greatly reduced, resulting into more effective learning. Further, there are other benefits associated with VR that include cost-saving, safety, and convenience [5].

This study is a general approach that explores the attitude of learners in Business Information Systems (BIS) program, Faculty of commerce, Helwan University, Cairo, Egypt for applying virtual reality technology in education.

\section{Background}

Higher education has evolved in the last decade with the use of information technology. This change was called distance education, a teaching method in which the student does not need to meet with the teacher on a certain day and time. The student may be either at home or at work and may have no interaction with the other parts, either the teacher or other students. Distance education has allowed the institutions to resolve geographical gaps in order to reach the largest number of students. On the other hand, it paved the way for the "nontraditional" universities oriented for "adult work", in a narrow range of graduation programs, compatible with the current demands from industry [6].

Distance Education upgrading the education system for learners who cannot able to study at institutions. It helps students for acquiring wider opportunities to join higher education. The distance education is very helpful for the student and the people who cannot involve in regular courses. The distance education system not only reduced the initial fear of students but also opened various dimensions of correspondences in education field. The distance education institution may be the best option for increasing the literacy rate in education [7].

Many approaches for education can be discussed: firstly, full time education secondly, part time education which allow learner to learn part in a college and other as distance and finally, distance education based on virtual reality [6]. Full time education is the traditional type of education and the most widely used approach in normal courses at any level, requiring teachers and students to be together in the classroom. The second approach combines learning in the classroom and at a distance using modern technology as VR. Distance education may or may not need to have face-to-face moments as teachers and students are physically separated in space or in time, while being able to interact through communication technologies like virtual reality technology. Figure 2 represents the difference between traditional class room and virtual reality in real life education.

\section{Related work}

Virtual reality technologies have the potential of making students feeling more dedicated and interested [8].
Researches on these technologies allows new trails for teaching [9]. There are many studies that investigate this area when using virtual reality technologies in educational process [10] [11], but these studies tend to be focused on specific experiences and topics. In addition is still not a clear vision of how to integrate these technologies in a stable way into an educational process. In this regard, there are difficulties like the resistance of traditional learning environments to integrate educational innovations, the opposition of teachers to adopt new technologies out of their comfort zone, and the costs involved to implement and maintain these technologies. However, taking into consideration the quick evolution of mobile technologies like smartphones and tablets, the use of VR is more feasible and affordable for educational institutions and students than ever before. Many application is built for educational propose. Jamed, Sharad (2017) built virtual reality instructional (VRI) modules based on gaming metaphors [12]. Travassos, Machado, Maciel (2013) presented a new system of learning a curricular unit of circuit theory using desktop virtual reality. The software provides the possibility to understand the relationship between the physical concepts of an electrical circuit [6].
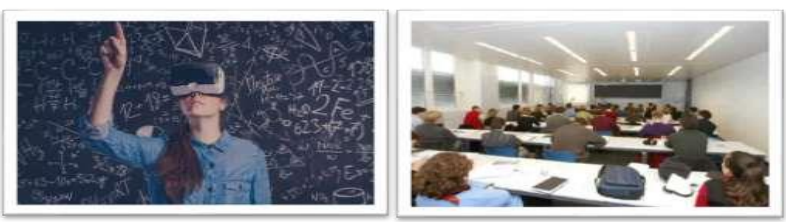

Figure 2: Difference Between Traditional Classroom and Virtual Reality in real life education

\section{Methodology and Empirical Study}

Business Information Systems program, Faculty of commerce, Helwan University, Cairo, Egypt has been chosen as the main source of data for this research. Structured questionnaire, primary data collection and different secondary data have been used for this study. After correction and validation the questionnaire, 1153 questionnaires distributed to the students. Only 729 students' responses on this questionnaire. The statistical analysis was used to identify the opportunities of VR in education process and its constraints in colleges in Egypt. Cross tabulation was conducted after frequency analysis on the respondents' answers and the results are tabulated in the results section. Figure 3 shows the methodology of research.

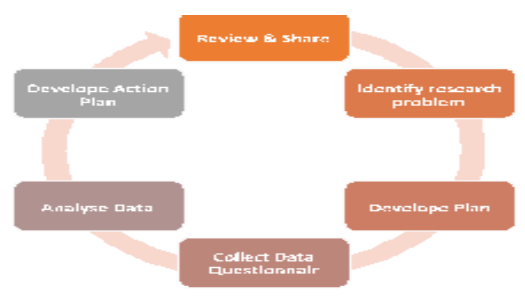

Figure 3: Methodology of research 
The questionnaire that distributed to students is measuring the importance of applying VR in educational process in BIS. In addition, measuring to what extend the students aware with VR technology. Moreover, determining the factors effected on the current education process which led to use new technology in education.

\section{Experiment and Results}

The following figures represent the responses for each question in questionnaire and the analyzing of these responses. These responses categorized into four sections. Each one shows specific aspects in the questionnaire.

\subsection{Personal information}

The analysis from questionnaires' responses showed that $59.3 \%$ of students were female and $40.7 \%$ were male that represented in figure 4 . Referring to figure 5 , most of the students were in level 3, 4, 2, 1, or graduated respectively. This study found that the highest numbers of students $36.2 \%$ having GPA between 2.8 to 3.39 out of 4.00 as shown in Figure 6

By analyzing the previous responses notice that most of learners who was participating in this questionnaire in the third and fourth level, this is means students learned in the current environment of education process and needing to new methods for acquiring learning content. In addition, the Cumulative GPA between $2.8 \& 4$ 4.00. This is means the academic level of learners is very good and leaners don't prefer VR technology for relaxation but to improve the quality of education process

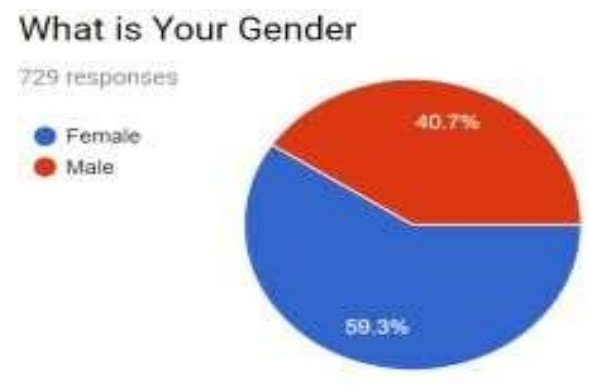

Figure 4: Respondents gender

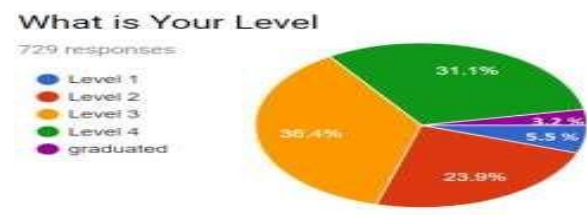

Figure 5: Respondents Academic Level

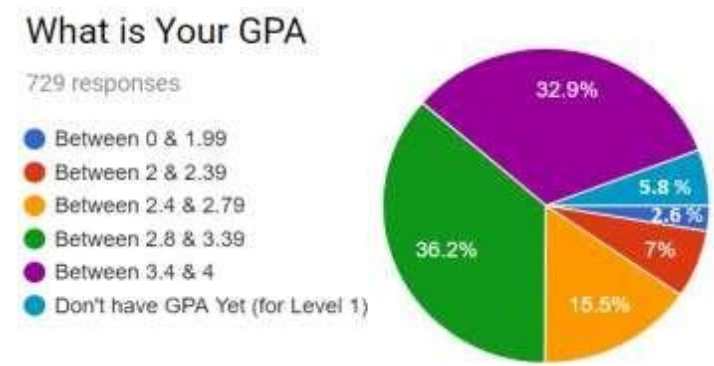

Figure 6: Respondents Academic GPA

\subsection{Relevant Factors}

The following responses measured the effective of cost, location, and relaxation factors for applying VR in education process. figure 7 displayed more than $70 \%$ of students stay away from the college with a distance of not less than $30 \mathrm{~km}$. As shown in figure 8 least $71.5 \%$ using public transportations for going to college like buses or metro and less than $28.5 \%$ using private transportations like taxi or owned car. $53.4 \%$ spent between 10 and 25 pound for going to college and $23.7 \%$ spent between 25 and 50 pound that represented in figure 9 . As illustrated in figure 10 , most of the students own smart phones compared to others devices

\section{In which region are you located}

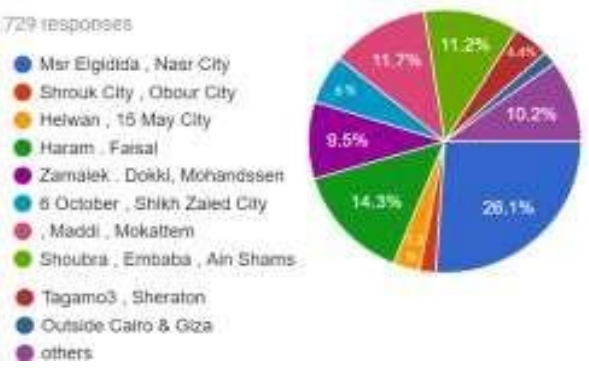

Figure 7: Respondents Location

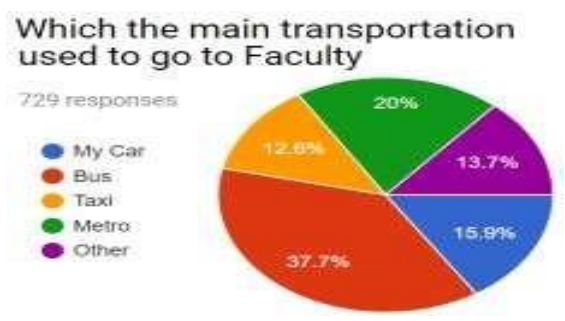

Figure 8: Transportation Used to College 


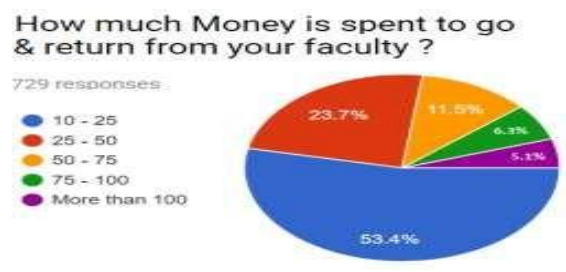

Figure 9: Transportation Used to College

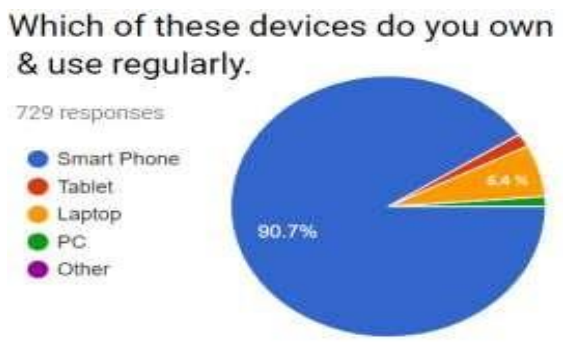

Figure 10: Best Device Used Regularly

The previous section refers to the needing of applying VR technology in education is increasing. Because of cost, location, relaxation factors. Most of learners locate far of the college and other spent more money to go college, while some of learners use uncomfortable transportation for going to college. All of these factors effects on the quality of education process. In addition, if applying VR in education we not have any problem in how to use it because of more than $90 \%$ using smart phones that used to run VR applications

\subsection{Awareness of GR}

In this section the researcher trying to know to what extend the students aware with VR technology and whether they know how to use this technology in general or not. Figure 11 showed that $40.6 \%$ of students just aware of VR, $30 \%$ else aware and use VR before, and $29.4 \%$ of students not aware of VR. In addition, most of students don't use VR applications. And others use them sometimes that represented in figure 12. As shown in figure 13 which displayed only $9.6 \%$ use VR in educational purpose, $35.4 \%$ use it for playing games, and the reminder of students don't use it. Finally figure 14 reviewed that $56.2 \%$ prefer elearning for lectures. And $32.1 \%$ still prefer to attend lectures in the group. But $11.7 \%$ prefer individual lectures (peer to peer

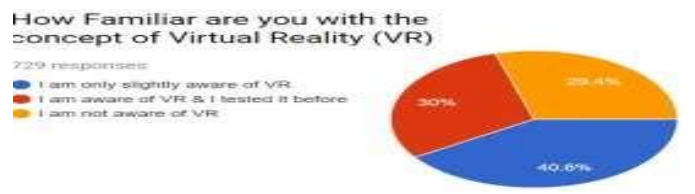

Figure 11: aware of VR

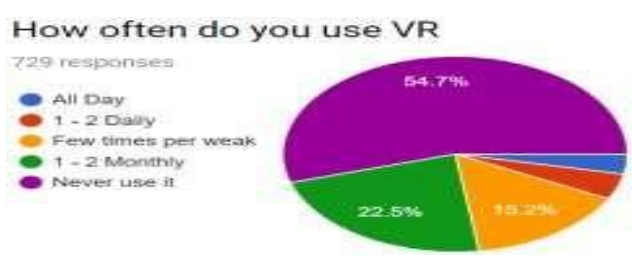

Figure 12: How often using VR

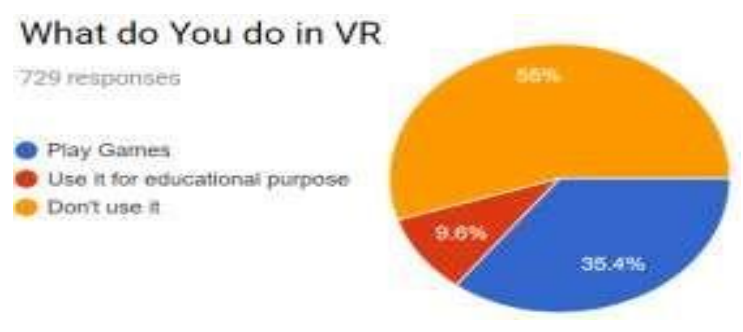

Figure 13: what do you do in VR

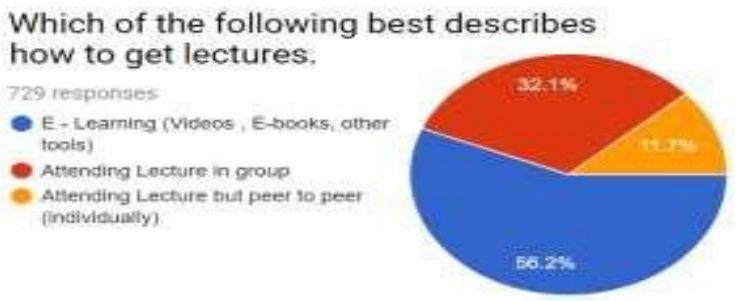

Figure 14: How to get lectures

It is clear that virtual reality technology has become known to most students but the majority of them have not used it before. In addition to the importance of e-learning for most students, the application of virtual reality technology in education will benefit students and accept it, this will be seen in the next section

\subsection{Attitudes of applying VR in education}

Finally, the following responses represents the attitudes of BIS students for applying VR in education. In figure 15 showed that the lack in educational environment is the most problem in education process. On the other hand the least problem is doctor can't control on lecture. For the importance of VR in education. Figure 16 showed that $56 \%$ said yes while around $10 \%$ said no. Finally, in term of participating in VR lectures the responses in figure 17 displayed that $55.1 \%$ of students will participate in VR Lectures for any course. And $37.6 \%$ of them will participate based on course type. While $7.3 \%$ not participate in VR lectures 


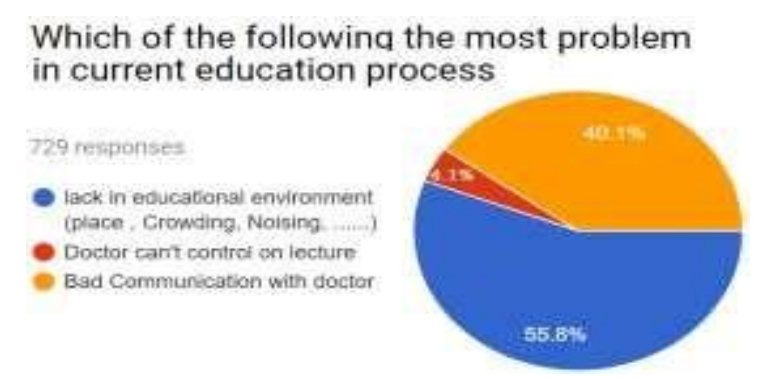

Figure 15: most problem in current education process

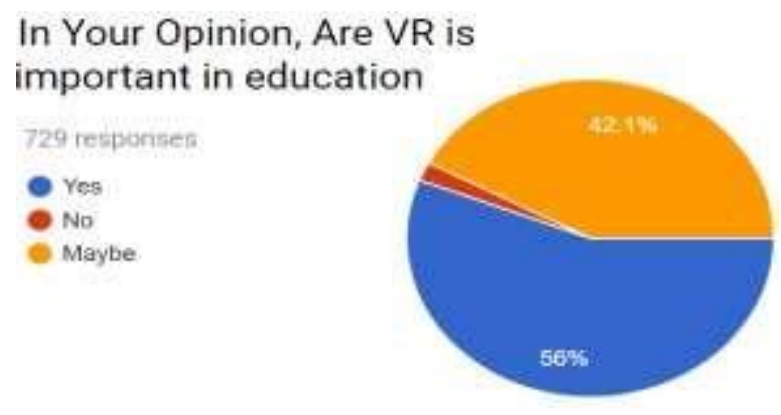

Figure 16: importance of VR in education

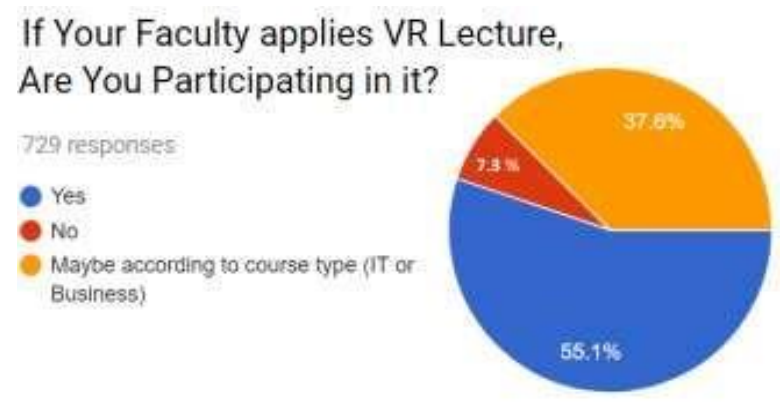

Figure 17: participating in VR lectures

As a result of the problems currently faced by students in the traditional educational environment, which is characterized by the weakness of the possibilities available and the lack of quality of the surrounding environment, which helps to benefit from the educational process, it is necessary to look for other ways to help raise the efficiency of the educational process. The use of virtual reality technology in educational process is one of the modern solutions that will help. Students are also fully prepared to use this technology and interact with it

\section{Conclusion and future work}

With the continuous development of information technology in different fields, especially in the field of education, as well as with the differences in the environment and the factors affecting the educational process, it was necessary to find a modern way to help raise the efficiency of the educational process and in line with this development in information technology. In this study, students' attitudes in the Business Information Systems program, Faculty of commerce, Helwan University, Cairo, Egypt were measured using virtual reality technology as a modern way of teaching. As well as to know the current problems facing them. This study shows that most students prefer to use this technology in education process and will participate if it is implemented.

\section{REFERENCES}

[1] L. Jonathan, "Unity Virtual Reality Projects. " , Hand Book, 2015.

[2] F. Graur, "Virtual Reality in Medicine - Going Beyond the Limits. " , Book Chapter in "Thousand Faces of Virtual Reality. " E-Book , November 2014.

[3] L. ERICKSON,"Entering the Metaverse: Your Guide To Joining The Virtual Reality Industry. ", E-Book, 2016.

[4] K. Zhang, S. J. Liu, "The Application of Virtual Reality Technology in Physical Education Teaching and Training. " , IEEE International Conference in Service Operations and Logistics, and Informatics, 245-248, 2016.

[5] N. Kulkami, "Virtual Reality in E-Learning Redefining the Learning Experience. " , Rapid Value solutions White Paper, 1-9, 2016.

[6] Valdez, M. T., Ferreira, C. M., and Barbosa, F. P. M. "Distance Education Using A Desktop Virtual Reality (VR) System. ", proceedings of the 24th Conference of European Association for Education in Electrical and Information Engineering, 145 -150, 2013

[7] R. Gupta, "Impact of ICT in Distance Education and Teacher Perception Towards Knowledge of ICT Tools.", International journal of Research and Granthaalayah, 5(1):163-171, 2017

[8] L. Kerawalla, R. Luckin, S. Seljeflot, and A. Woolard, " Making It Real: Exploring the Potential of Augmented Reality For Teaching Primary School Science. ", Intenational Journal on Virtual Reality 10(3): 163-174, 2006.

[9] C. M. Chen, and Y. N. Tsai, "Interactive Augmented Reality System For Enhancing Library Instruction In Elementary Schools. ", International Journal in Computers and Education, ", 59(2):638-652, 2012. 
Future Computing and Informatics Journal, Vol. 4 [2019], Iss. 1, Art. 2

[10] D. Serio, M. B. Ibáñez, and C. D. Kloos, " Impact of an Augmented Reality System On Students' Motivation For A Visual Art Course. "International Journal in Computers and Education, 68(1):586-596, 2013.

[11] J. Martín-Gutiérrez, J. L. Saorín, M. Contero, M. Alcaniz, D. C. Pérez-López, and M. Ortega, M., " Design and Validation of an Augmented Book For Spatial Abilities Development in Engineering Students. ", International Journal in Computers and Graphics, 34(1):77-91, 2010. 